\title{
Electromyographic Activity of Masticatory Muscles in Women with Osteoporosis
}

\author{
Selma SIÉSSERE \\ Luiz Gustavo de SOUSA \\ Naira de Albuquerque LIMA \\ Marisa SEMPRINI \\ Paulo Batista de VASCONCELOS \\ Plauto Christopher Aranha WATANABE \\ Sandra Valéria RANCAN \\ Simone Cecilio Hallak REGALO
}

Ribeirão Preto Dental School, University of São Paulo, Ribeirão Preto, SP, Brazil

\begin{abstract}
The purpose of this study was to analyze the electromyographic (EMG) activity and the maximal molar bite force in women diagnosed with osteoporosis in the maxillary and mandibular regions, considering the habits and conditions that lead to development of generalized skeletal bone loss, including on face bones, can disturb the functional harmony of the stomatognathic system. Twenty-seven women with mandibular and maxillary osteoporosis and 27 healthy controls volunteered to participate in the study. A 5-channel electromyographer was used. Muscle activity was evaluated by means of EMG recordings of the masticatory musculature (masseter and temporalis muscles, bilaterally) during the following clinical conditions: rest $(5 \mathrm{~s})$; right and left lateral excursions ( $5 \mathrm{~s})$; protrusion (5 s); maximal dental clenching on Parafilm ${ }^{\mathrm{TM}}(4 \mathrm{~s})$ and maximal voluntary contraction (4 s). This latter clinical condition was used as the normalization factor of the sample data. It was observed that individuals with osteoporosis presented greater EMG activity when maintaining mandible posture conditions and less activity during dental clenching and when obtaining maximal molar bite force. It may be concluded that facial osteoporosis can interfere on the patterns of masticatory muscle activation and maximal bite force of the stomatognathic system.
\end{abstract}

Key Words: electromyography, osteoporosis, masticatory muscles.

\section{INTRODUCTION}

Osteoporosis is a pathologic condition defined as the absolute reduction in bone quantity and damage of its micro-architecture structure, thus leading to a state of fragility in which fractures can occur after minor traumas. It is characterized by the reduction of bone mass and the disorganization of the trabecular architecture, with consequent weakening of the bone (1). It is considered a serious public health issue and one of the most important aging-associated diseases, affecting millions of people in the world (2). As any other health hazard, osteoporosis affects one's self-esteem, causes complications to the family routine, in addition to generating costs to the public administration and also to the patient with its treatment (3). Until the age of 30 , approximately, the amount of bone that is reabsorbed and replaced is the same. After this age, a slow negative balance appears and will cause slight bone mass loss at the end of each remodeling unit activation (4). Hence, a slow age-related bone mass loss process begins - senile osteoporosis - in which, through life, women will loose about $35 \%$ of cortical bone and $50 \%$ of trabecular bone, while men lose $2 / 3$ of that amount (1).

Studies on osteoporosis related to the most common affected human body parts, like the back, femur neck, wrist (1), and, current research about face bones (2) can be found in the literature. However, there are no studies that include the analysis of muscle activity and maximal bite force of the stomatognathic system. 
According to Francischone and Tavano (5) the maxillary signs for osteoporosis can be important indicatives of this degenerative disease, and thus may interfere in the dentist's conduct, for instance bone-integration surgeries.

Knowledge of one's maxillary bone conditions, muscle function and bite force, as well as preventively warning patient and dentist about the clinical and social importance of detecting this disease is essential to provide the bases for the therapeutic planning. Therefore, the purpose of this study was to analyze the EMG activity and the maximal molar bite force in women diagnosed with osteoporosis in the maxillary and mandibular regions.

\section{MATERIAL AND METHODS}

\section{Volunteers}

Twenty-seven 50-70-year-old women with no distinction of ethnicity or social class were enrolled in the study. All volunteers had mandibular and maxillary osteoporosis, which had been diagnosed by identification of low mineral bone mass on panoramic radiographs, which was confirmed by bone densitometry. Subjects were selected at random from users of the Radiology Clinic at Ribeirão Preto Dental School, University of São Paulo, Brazil. The control group consisted of employees, and patients' and students' relatives paired subject-to-subject with the patients with osteoporosis.

The sample and inclusion/exclusion criteria were established by means of clinical interview and examination. The clinical interview provided information regarding the participants' personal data, medical and dental history, any existing parafunctional habits, and possible temporomandibular dysfunction symptoms. All subjects were completely dentate or orally rehabilitated by means of partial fixed dentures or dental implants, and had no periodontal problems. Eligible participants were excluded if they had any one of the following exclusion criteria: 1 . Presenting any systemic or local disorders other than osteoporosis that could compromise the craniofacial growth or the masticatory system, like neurological disorders, cerebral palsy, and others; 2 . Using any medication that could interfere in muscle activity, such as anti-histamines, sedatives, syrups, homeopathy, or central nervous system depressors; 3 . Receiving any kind of treatment that could, directly or indirectly, interfere in muscle activity during the course of the study, such as speech therapy and otorhinolaryn- gology treatment.

Subjects were informed about the purposes and stages of the study and they all gave written consent, signing an informed consent form previously approved by the local Research Ethics Committee according to the Brazilian National Health Council (process \#2006.1.242.58.3).

Randomization was done selecting every odd number patient from the list off individuals with osteoporosis to then carry out the EMG and bit force exams.

When 27 patients had agreed to participate in the study, the search for the 27 control subjects started, who were paired subject-to-subject with the osteoporosis sample. Each subject was assigned into one of 2 groups, names 1 and 2, and only 1 examiner knew which group the numbers referred to - control or osteoporosis. All exams were performed without the researchers knowing to which group the studied subject belonged, which made the present study a double-blind investigation.

\section{EMG and Bite Force Analyses}

The EMG signals and bite force measures were collected simultaneously, with the volunteers sitting on a comfortable office-like chair, with the arms extended along the body and the hands lying on their thighs.

Muscle activity was evaluated by means of EMG recordings of the masticatory musculature (masseter and temporalis muscles, bilaterally) during the following clinical conditions: rest $(5 \mathrm{~s})$; right and left lateral excursions $(5 \mathrm{~s})$; protrusion $(5 \mathrm{~s})$; maximal dental clenching on Parafilm ${ }^{\mathrm{TM}}$ (American National Can., Greenwich, CT, USA) (4s) and maximal voluntary contraction ( $4 \mathrm{~s})$. This latter clinical condition was used as the normalization factor of the sample data.

The EMG analysis was performed using a 5-channel electromyographer (Myosystem-Br1; DataHomins Ltda. Uberlândia, MG, Brazil) with simultaneous acquisition, common grounding to all channels, low-pass filters of $10 \mathrm{~Hz}$ to $5 \mathrm{KHz}$; channel input impedance of 10 $\mathrm{G} \Omega$ in differential mode, 12 bites of dynamic resolution range, amplitude band of $-10 \mathrm{~V}$ to $+10 \mathrm{~V}$, and channel sampling frequency of $2 \mathrm{KHz}$. The software Myosystem I, version 3.5, was used for signal visualization and processing, also allowing, after digitalization, the signals to be analogically amplified with a $\times 1000$ gain, filtered by a $0,01-1,5 \mathrm{kHz}$ bandpass filter and sampled by a 12-b $\mathrm{A} / \mathrm{D}$ converter with an acquisition frequency of $2 \mathrm{kHz}$. 
Surface differential active electrodes (two 10 $\mathrm{mm}$-long and $2 \mathrm{~mm}$-wide silver-chloride bars, separated by a distance of $10 \mathrm{~mm}$, with input impedance of $10 \mathrm{G} \Omega$ and common-mode rejection ratio of $130 \mathrm{~dB}$ at $60 \mathrm{~Hz}$ ) were used in the study. The skin region where electrodes were placed was cleaned with alcohol and shaved when necessary. The differential active electrodes were positioned in the ventral region of both masseter muscles and in the anterior portion of the left and right temporalis muscles. The position of the electrodes was determined by palpation and they were fixated with adhesive bandage tape, with the longest extension of the bars perpendicular to the direction of the muscle fibers. A stainless still circular electrode ( $3 \mathrm{~cm}$ of diameter) was also used as a reference electrode (ground electrode), fixated on the skin over the frontal bone region.

Bite force records were taken with a digital dynamometer, model IDDK (Kratos, Cotia, SP, Brazil), with a $100 \mathrm{Kgf}$ capacity, adapted to the mouth. The apparatus has an indicator in Kgf and N, and a "set-zero" key, which allows the exact control of the values obtained and also "peak" registers, that facilitates the record of the maximal force during measures. It has 2 arms with plastic disks on each end, over which the force to be measured is applied. Its high-precision charge cell and electronic circuit to indicate force, supply precise measures easily viewed on a digital display. The dynamometer was cleaned with alcohol and disposable latex finger cots (Wariper Produtos Assépticos e Descartáveis Ind e Com Ltda., São Paulo, SP, Brazil) were positioned on the biting arms as a biosecurity measure. The participants were given detailed instructions and bite tests were performed before the actual recordings were made, in order to ensure the reliability of the procedure. The volunteers were then asked to bite the dynamometer 3 times with maximal force, with a 2-mat rest interval between records. Evaluations were performed in the first molar (left and right). Maximal bite force was measured in N through the "peak" force record indicated on the screen for subsequent analysis. The highest value out of 3 records was considered as the individual's maximal bite force.

Before each experiment, subjects received the necessary instructions and explanations, and were asked to remain as calm as possible, and to breath slowly.

\section{Statistical Analysis}

The EMG signals were processed, analogically amplified (with a $\times 1000$ gain), filtered $(0.01-1.5 \mathrm{kHz}$ pass-band filter) and sampled by a 12 12-b A/D converter with an acquisition frequency of $2 \mathrm{kHz}$. The gross EMG signal was used to derive EMG amplitude values, obtained by calculating the root mean square (RMS). The RMS values obtained during maximal voluntary contraction were used to normalize the values in the other clinical situations (6). The statistical analysis was performed using the SPSS software (SPSS Inc., Chicago, IL, USA). Student's t-test was used for group comparison $(\alpha=0.05)$.

\section{RESULTS}

During the clinical mandible posture conditions, like rest, right and left lateral excursions, and protrusion, it was observed that the subjects with osteoporosis showed greater EMG activity for all the analyzed muscles, compared to control subjects, without osteoporosis. For maximal dental clenching, however, control subjects presented greater EMG activity with a tendency for statistical significance at $\mathrm{p}<0.05$.

Table 1 shows the EMG values of the normalized (mean and standard error) RMS of the masseter and temporalis muscles (right and left) under the different clinical conditions for patients with osteoporosis and control subjects.

In the analysis of maximal bite force between groups (Table 2), control individuals presented greater bite force $(p<0.01)$ in the molar region.

\section{DISCUSSION}

The osteoporosis affects millions of people worldwide (2), mostly women. Men can also be affected and its early diagnosis is essential.

The alterations cause by osteoporosis deserve special attention from dentists, especially because it is a common metabolic bone disease after the age of 40 , having fractures and muscle loss as the most evident clinical manifestations. Osteoporosis induces the resorption of the alveolar bone, with poor bone formation, which causes an unbalance and deterioration of the stomatognathic system. The mucosa presents a reduced number of receptors, thus reducing the number of afferent impulses. This consequently affects muscle control and activity, in addition to the associated changes to the temporomandibular joint. These factors determine important 
functional changes and thus bring about limiting factors in maintaining a normal stomatognathic system (7).

Table 1. Normalized root mean square (RMS) values for right masseter (RM), left masseter (LM), right temporalis (RT) and left temporalis (LT) muscles in osteoporosis and control groups.

\begin{tabular}{llll}
\hline $\begin{array}{l}\text { Clinical } \\
\text { conditions } \\
\text { and muscles }\end{array}$ & Osteoporosis & Control & Significance \\
\hline
\end{tabular}

Rest

$\begin{array}{llll}\text { RM } & 0.16 \pm 0.03 & 0.14 \pm 0.04 & * \\ \text { LM } & 0.20 \pm 0.03 & 0.18 \pm 0.04 & \text { ns } \\ \text { RT } & 0.25 \pm 0.05 & 0.19 \pm 0.04 & \text { ns } \\ \text { LT } & 0.19 \pm 0.03 & 0.11 \pm 0.01 & *\end{array}$

Right laterality

$\begin{array}{llll}\text { RM } & 0.24 \pm 0.05 & 0.17 \pm 0.04 & * \\ \text { LM } & 0.28 \pm 0.05 & 0.24 \pm 0.04 & \text { ns } \\ \text { RT } & 0.32 \pm 0.07 & 0.21 \pm 0.04 & * \\ \text { LT } & 0.24 \pm 0.07 & 0.12 \pm 0.01 & \text { ns }\end{array}$

Left laterality

$\begin{array}{llll}\text { RM } & 0.26 \pm 0.05 & 0.20 \pm 0.03 & * \\ \text { LM } & 0.22 \pm 0.04 & 0.19 \pm 0.04 & \text { ns } \\ \text { RT } & 0.24 \pm 0.05 & 0.17 \pm 0.03 & \text { ns } \\ \text { LT } & 0.27 \pm 0.08 & 0.14 \pm 0.01 & \text { ns }\end{array}$

Protrusion

$\begin{array}{llll}\text { RM } & 0.37 \pm 0.08 & 0.34 \pm 0.05 & \text { ns } \\ \text { LM } & 0.35 \pm 0.09 & 0.34 \pm 0.06 & \text { ns } \\ \text { RT } & 0.26 \pm 0.06 & 0.18 \pm 0.04 & * \\ \text { LT } & 0.33 \pm 0.15 & 0.11 \pm 0.01 & \text { ns }\end{array}$

Dental

Clenching

\begin{tabular}{llll} 
RM & $1.44 \pm 0.17$ & $1.44 \pm 0.15$ & ns \\
LM & $1.37 \pm 0.13$ & $1.59 \pm 0.16$ & ns \\
RT & $1.32 \pm 0.23$ & $1.32 \pm 0.12$ & ns \\
LT & $1.10 \pm 0.09$ & $1.11 \pm 0.06$ & ns \\
\hline
\end{tabular}

*indicates statistically significant difference at $\mathrm{p}<0.05$; ns $=$ nonsignificant.
The evaluation of masticatory muscle EMG activity also has become more and more useful to dentists since it adds to the knowledge of muscle performance during mandibular rest, during regulating reflex movements, and in the changes to muscle patter $(8,9)$. The stomatognathic system is a physiological and functional entity formed by a set of structures working harmoniously during the function of chewing (10). For the subjects to achieve craniofacial balance, and have normal growth and development, the treatment for the changes should be established as soon as the dysfunctions are diagnosed. There are several diseases that can affect the stomatognathic system, causing its unbalance and bad functioning, and osteoporosis is one of them.

In this study, the EMG analysis allowed evaluating the EMG activity of the masseter and temporalis muscles (both sides) at rest and in mandible posture conditions. There were changes in the muscle activation pattern resulting from the osteoporosis of the mandible and maxillary bones.

The fact that subjects with osteoporosis presented greater EMG activity during rest and on right and left lateral excursions and protrusion, compared to the activity developed by individuals without osteoporosis (control) in the same clinical situations, can be a sign of a muscular dysfunction of the stomatognathic system caused by the loss of bone tissue in the region of the head bones. It was observed that subjects with osteoporosis need greater muscle activation to maintain the same positions of subjects in the control group. Several studies have shown that muscles do not present any electrical activity at rest, i.e., there are no motor unit contractions (11), though some authors have indeed found minimal muscle activity involved with the mastication process (12). Harper et al. (13) found that the rest position is maintained by low levels of tonic activity of mastication muscles, it is controlled by sensorial receptors and the central nervous system, and that changes in those systems can cause changes in function and muscle tension.

Table 2. Maximal bite force (N) and standard-error (Student's t-test ) in the molar regions in each experimental group.

\begin{tabular}{lccc}
\hline Region & Osteoporosis & Control & Significance \\
\hline Right Molar & $105 \pm 6$ & $230 \pm 16$ & $*$ \\
Left Molar & $117 \pm 7$ & $214 \pm 22$ & $*$ \\
\hline
\end{tabular}

*indicates statistically significant difference at $\mathrm{p}<0.01$ 
In this study, it was observed that, during the clinical condition of masticatory muscle rest, women with osteoporosis as well as controls were able to maintain mandibular rest with very low EMG activity, similar to that observed by Sgobbi and Bérzin (14), who found that clinically normal subjects presented minimal EMG activity for the masseter and temporalis muscles. According to Pinho et al. (15) the EMG activity of mastication muscles at rest is greater in patients with stomatognathic system dysfunctions, compared to healthy individuals. This suggests there is an increase in basal tonus, which agrees with the findings of the present study in which subjects with osteoporosis presented increased EMG activity. These data are similar to those of a previous study (16) in which patients with malocclusion made a stronger effort to make the movements, probably due to muscle unbalance, which makes normal function more difficult.

It has been observed that control subjects with complete dentition show their maximal EMG activity of the masseter muscles during dental clenching (17), which agrees with the present study results for the 2 evaluated groups. While performing the clinical condition of dental clenching, it was observed that the masseter muscles showed greater EMG activity than the temporalis muscles in subjects from either the control or osteoporosis group, with a balance between the normalized mean values of the masseter and temporalis. This fact is due to the morphologic and functional characteristics of these muscles. The masseter is a strong muscles with a force function, whereas the temporalis musculature is more associated with speed, is the first to contract during maxillary closing, and is considered a mandible positioner $(13,18)$. Klemetti et al. (19) observed that the force of the masseter muscle over the alveolar ridge has a direct relation with maintaining the mineral density of bone tissue.

Regarding the clinical conditions of right and left laterality and protrusion, subjects with osteoporosis presented greater EMG activity. For protrusion, both analyzed groups showed the EMG contraction pattern expected for maintaining this posture, which consists in a greater activation of the masseter muscle compared to the temporalis muscle activity.

There is a balance between the masseter and temporalis muscles during the maintenance of postural position in subjects with osteoporosis compared to controls, which makes the osteoporosis group closer to the type of balanced muscle relationship developed by the control group. It is possible that, as years go by, this small variation may increase and make those differences more evident, thus calling for a longitudinal study to observe the strongest effects of osteoporosis over time.

In the maximal bite force analysis, the individuals of both groups were properly instructed and collaborated with the experiment. The standardization of the methodology and the performance of 3 repetitions with 2-min intervals between each for obtaining the maximal bite force were accomplished so that errors and interferences were minimized. A digital dynamometer with 2 arms with plastic disks on each end, over which the force to be measured was applied. Its high precision charge cell and electronic circuit indicate the force and supply precise and easily readable measures on the digital display. The diameter of the arms, together, is of approximately $10 \mathrm{~mm}$, adequate for an oral aperture that does not interfere in the force employed, preventing muscular strain (or even suboptimal sarcomere length) and exaggerated displacement of the condyles (20). Maximal molar bite force (to the right and left sides), as in the case of dental clenching, was greater in control subjects. This result is statistically significant and shows that the osteoporosis factor affects obtaining the maximal force of the stomatognathic system and leads to a reflection about whether this data can affect the subjects' masticatory patterns. Hence, it is emphasized that further studies are needed to make a comparison between age groups and genders, and long-term investigations should be performed to assess the masticatory and muscular function of subjects with osteoporosis.

It may be concluded that mandibular and maxillary osteoporosis induces changes to the stomatognathic system, affecting the normal activities of the masticatory muscles, and promoting increased EMG activity at rest, during right and left lateral excursions and protrusion. Decreased EMG activity was observed for maximal dental clenching as well as for the maximal bite force in the right and left molar regions.

\section{RESUMO}

Este estudo teve como objetivo analisar a atividade eletromiográfica e a força de mordida molar máxima de indivíduos diagnosticados com osteoporose na região maxilar e mandibular, visto que os hábitos e condições que provocam o desenvolvimento 
de uma perda óssea generalizada no esqueleto, inclusive no esqueleto facial, podem causar distúrbios na harmonia funcional do sistema mastigatório. Vinte e sete indivíduos portadores de osteoporose na mandíbula e maxila e 27 voluntários sem a doença participaram deste estudo. Um eletromiógrafo de 5 canais foi utilizado. A avaliação da atividade muscular foi realizada por meio de registros eletromiográficos da musculatura mastigatória (músculos masseter e temporal, bilateralmente) durante as seguintes condições clínicas: Repouso (5 s); Lateralidades direita e esquerda (5 s); Protrusão (5 s); Apertamento dental máximo com parafilme (4 s) e a contração voluntária máxima (4 s), sendo que esta condição clínica foi utilizada como fator de normalização dos dados da amostra. Verificou-se que os indivíduos com osteoporose apresentaram maior atividade eletromiográfica durante a manutenção das condições posturais da mandíbula e menor atividade durante o apertamento dental e na obtenção da força de mordida molar máxima. Conclui-se que a osteoporose na região dos ossos da face pode interferir nos padrões de ativação da musculatura mastigatória e na força de mordida máxima do sistema estomatognático.

\section{ACKNOWLEDGEMENTS}

This study was supported by FAPESP (grant \#2006/53563-9) and CNPq (2008.1.356.58.0).

\section{REFERENCES}

1. Lane NE. Epidemiology, etiology, and diagnosis of osteoporosis. Am J Obstet Gynecol 2006;194:S3-S11.

2. Samelson EJ, Hannan MT. Epidemiology of osteoporosis. Curr Rheumatol Rep 2006;8:76-83.

3. Atik OS, Gunal I, Korkusuz F. Burden of osteoporosis. Clin Orthop Relat Res 2006;443:19-24

4. Mundy GR. Nutritional modulators of bone remodeling during aging. Am J Clin Nutr 2006;83:427S-430S.

5. Issa JPM, Tiossi R, Catirse ABCEB, Monteiro SAC, Watanabe PCA.Comparative bilateral bone density of the mandible angle. Int J Morphol 2007;25:337-340.

6. Seniam - Biomedical and Health Research Program. European Recommendations for Surface Electromyography. Viena: Roessingh Research and Development; 1999. Hermens HJ, Freriks B, Merletti R, Stegeman D, Blok J, Rau G, et al..

7. Piancino MG, Farina D, Talpone F, Castroflorio T, Gassino G, Margarino V, et al.. Surface EMG of jaw-elevator muscles and chewing pattern incomplete denture wearers. J Oral Rehabil 2005;32:863-870.
8. Regalo SCH, Vitti M, Hallak JEC, Semprini M, Matos MGC, Tosello DO, et al.. EMG analysis of the upper and lower fascicles of the orbicularis oris muscle in deaf individuals. Electromyogr Clin Neurophysiol 2003;43:367-372.

9. Regalo SCH, Vitti M, Moraes MTB, Semprini M, Felício CM, Mattos MGC, et al.. Electromyographic analysis of the orbicularis oris muscle in oralized deaf individuals. Braz Dent J 2005; 16:237242.

10. Gavião MBD, Raymundo VGR, Sobrinho LC. Masticatory efficiency in children with primary dentition. Ped Dent 2001;26:499505.

11. Chong SS, Ouyang G, Tian WG. Power spectral analysis of electromyographic signal of masticatory muscles at rest position and habitual clench. J Prosthet Dent 1991;65:553-556.

12. Regalo SC, Vitti M, Semprini M, Rosa LB, Martinez FH, Santos $\mathrm{CM}$, et al.. Electromyographic analysis of the masseter and temporal muscles in oralized deaf individuals. Electromyogr Clin Neurophysiol 2006;46:17-22.

13. Harper RP, Bruin H, Burcea I. Muscle activity during mandibular movements in normal and mandibular retrognathic subjects. J Oral Maxillofac Surg 1997;55:225-233.

14. Sgobbi de Faria CRS, Berzin F. Electromyographic study of the temporal, masseter and suprahyoid muscle in mandibular rest position. J Oral Rehabil 1998;25:776-780.

15. Pinho JC, Caldas FM, Mora MJ, Santana-Penin U. Electromyographic activity in patients with temporomandibular disorders. J Oral Rehabil 2000;27:985-990.

16. Palomari ET, Vitti M, Tosello DO, Semprini M, Rodrigues AL. Electromyographic study of the masseter muscle in individuals with Class II malocclusion. Electromyogr Clin Neurophysiol 2002;42:71-77.

17. Blanksma NG, Van Eijden TM. Electromyographic heterogeneity in the human temporalis and masseter muscles during static biting, open/close excursions, and chewing. J Dent Res 1995;74:13181327.

18. Ueda MH, Ishizuka Y, Miyamoto K, Morimoto N, Tanne K. Relationship between masticatory muscle activity and vertical craniofacial morphology. Angle Orthod 1998;68:233-238.

19. Klemetti E, Vainio P, Kröger H. Muscle strength and mineral densities in the mandible. Gerodontology 1994;11:76-79.

20. Castelo PM, Bonjardim LR, Pereira LJ, Gavião MB. Facial dimensions, bite force and masticatory muscle thickness in preschool children with functional posterior crossbite. Braz Oral Res 2008;22:48-54.

Accepted August 11, 2009 